\title{
SISTEM PENDUKUNG KEPUTUSAN PENENTUAN PUPUK PADA TANAMAN PADI DI JAWA TIMUR MENGGUNAKAN METODE TECHNIQUE FOR ORDER PREFERENCE BY SIMILARITY OF IDEAL SOLUTION (TOPSIS) DAN WEIGHT PRODUCT (WP) BERBASIS WEB
}

\author{
Ira Indriastuti, Febriana Santi Wahyuni, F.X Ariwibisono \\ Program Studi Teknik Informatika S1, Fakultas Teknologi Industri \\ Institut Teknologi Nasional Malang, Jalan Raya Karanglo km 2 Malang, Indonesia \\ 1718063@scholar.itn.ac.id
}

\begin{abstract}
ABSTRAK
Tanaman padi merupakan hasil dari pertanian di Indonesia yang sangat dibutuhkan sebagai bahan pokok. Faktor terpenting dalam pembudidayaan tanaman padi adalah pupuk sebagai sumber keberhasilan dari penanaman padi. Penentuan pupuk bagi petani tanaman padi di Jawa Timur merupakan permasalahan yang penting karena tanaman padi merupakan kebutuhan pokok sehingga menyebabkan hasil panen dibutuhkan oleh dunia. Permasalahan di daerah adalah pemilihan pupuk bagi petani masih kurang efektif karena dalam pemilihan pupuk perlu melakukan survei ke Balai Pengkajian Teknologi Pangan. Pada penelitian ini menggunakan metode Technique For Order Preference By Similarity Of Ideal Solution Dan Weight Product sebagai penentuan pupuk tanaman padi yang disesuaikan dengan kondisi lingkungan dan kerusakan tanaman di Jawa Timur. Berdasarkan hasil dari penelitian didapatkan 8 kriteria yaitu status banjir padi, status kekeringan padi, status opt wereng batang coklat, status opt tikus sawah, status opt penggerek batang padi, status opt tungro, status opt blast, dosis, dan 6 alternatif yaitu non organic npk 15-15-15, non organic urea, non organic za, organic npk 15-15-15, organic urea, organic za. Sub kriteria kerusakan sangat tinggi, tinggi, sedang, rendah, aman dan sub kriteria dosis pupuk 50-99 $(\mathrm{Kg} / \mathrm{ha}), 100-149$ (Kg/ha), 150-199 (Kg/ha), 200-299 (Kg/ha), 300-350 (Kg/ha). Metode ini digunakan untuk menentukan alternatif yang ada untuk menyelesaikan masalah. Nilai alternatif didapatkan pada pemberian bobot nilai kriteria. Hasil dari penelitian menggunakan metode gabungan ini dengan status kerusakan tanamannya status banjir padi rendah, status kekeringan padi sedang, status opt wereng batang coklat sedang, status opt tikus sawah sedang, status opt penggerek batang padi sangat tinggi, status opt tungro tinggi, status opt blast rendah, dan dosis pupuknya sebesar 350,100,100,200,125, 100. Dari data tersebut menghasilkan nilai dengan skor 1 dengan kategori pupuk non organik npk 15-15-15 terekomendasi untuk keadaan kerusakan tanaman dan dosis pupuk sesuai keadaan di lapangan. Berdasarkan hasil dari penelitian memiliki nilai perhitungan manual dan sistem sebesar 0,089946, dapat disimpulkan penggabungan dua metode ini cukup efektif.
\end{abstract}

Kata Kunci : Sistem Pendukung Keputusan, Technique For Order Preference By Similarity Of Ideal Solution, Weight Product.

\section{PENDAHULUAN}

Tanaman padi merupakan hasil dari pertanian di Indonesia yang sangat dibutuhkan sebagai bahan pokok. Faktor terpenting dalam pembudidayaan tanaman padi adalah pupuk sebagai sumber keberhasilan dari penanaman tanaman padi. Pemupukan bertujuan untuk menjaga unsur hara pada tanaman padi agar berkembang dengan baik serta dapat terhindar dari hama dan penyakit. Di dalam pertanian memiliki jenis pupuk yang beragam.

Menentukan pupuk yang cocok bagi petani tanaman padi di Jawa Timur merupakan permasalahan yang terpenting karena hasil dari panen sangat dibutuhkan sebagai kebutuhan pokok. Permasalahan yang dialami adalah pemilihan pupuk di daerah masih kurang efektif. Karena dalam pemilihan pupuk para petani atau sektor usaha harus melakukan survei langsung ke Balai Pengkajian Teknologi Pangan untuk merekomendasikan jenis pupuk terbaik. Tetapi hal ini tidak efisien karena tidak menyesuaikan dengan tingkat keadaan dari kerusakan tanaman di daerah tersebut.
Pada tahun 2016 penelitian jurnal rekursif vol 4 yang berjudul "Sistem Pendukung Keputusan Pemilihan Jenis Kayu Untuk Mebel Dengan Metode Weighted Product dan Technique For Order Preference By Similarity To Ideal Solution" yang diteliti oleh Jhon Elan untuk menentukan kualitas produk mebel atau kerajinan kayu. Dalam penelitian ini Jhon Elan berhasil merancang dan mengimplementasikan menggunakan Bahasa pemrograman PHP. Aplikasi ini dapat berjalan sesuai fungsinya yaitu user dapat menentukan jenis kayu. Dari pengujian yang telah dilakukan didapat kesimpulan yang memiliki uji kedekatan $37 \%$.

Berdasarkan permasalahan tersebut, penulis mengangkat judul skripsi sistem pendukung keputusan penentuan pupuk pada tanaman padi menggunakan metode Technique For Order Preference By Similarity To Ideal Solution dan Weighted Product untuk menentukan alternatif yang ditawarkan dari penyelesaian masalah, nilai alternatif tergantung pada pemberian bobot nilai kriteria. Kriteria yang digunakan dalam sistem ini adalah tingkat kerusakan 
tanaman dan dosis pupuk. Metode Topsis didasarkan pada konsep dimana alternatif terpilih yang terbaik tidak hanya memiliki jarak terpendek dari solusi ideal positif namun juga memiliki jarak terpanjang dari solusi ideal negatif. Sedangkan metode Wp menggunakan perkalian untuk menghubungkan rating atribut, dimana setiap atribut harus dipangkatkan terlebih dulu dengan bobot atribut yang bersangkutan. Oleh karena itu, dari perbedaan proses perhitungan dari kedua metode tersebut, penelitian ini menggabungkan dari kedua metode tersebut yang belum banyak digunakan. Diharapkan dari penelitian ini memiliki hasil yang dapat digunakan secara efektif dari penelitian yang sudah ada.

\section{TINJAUAN PUSTAKA}

\subsection{Penelitian Terdahulu}

Pada tahun 2020 pada penelitian yang berjudul "Pemilihan Pupuk Pada Tamanam Padi Berbasis Web Untuk Meningkatkan Hasil Panen Dengan Menggunakan Metode Analitical Hierarcy Proses" yang diteliti oleh Wahyuni Yayan. Pada umumnya padi merupakan hasil pertanian yang dibutuhkan oleh masyarakat Indonesia. Pada penelitian sistem pendukung keputusan ini menggunakan metode Analytical Hierarchy Proses (Ahp) berbasis web untuk membantu user dalam membuat keputusan mengenai jenis pupuk benih padi yang akan mereka gunakan dan memberikan informasi berupa perangkingan. [1]

Pada tahun 2017 penelitian yang berjudul "Sistem Pendukung Keputusan Pemilihan Pupuk Untuk Tanaman Padi Menggunakan Metode Fuzzy" yang diteliti oleh Erwin Hermawan. Dengan lahan pertanian yang semakin sedikit tidak berpengaruh terhadap penggunaan pupuk bersubsidi, hal ini menjadi faktor sulit untuk mendapatkan pupuk yang memberikan kenaikan hasil panen tanaman. Dengan adanya aplikasi ini diharapkan dapat memberikan dampak yang signifikan terhadap penggunaan pupuk di masa mendatang secara terstruktur. Sistem pendukung keputusan berfungsi sebagai bentuk diagnose awal dengan teori pendukung terhadap kebutuhan tanaman padi. Sedangkan metode fuzzy Mamdani digunakan untuk memperoleh kesimpulan menggunakan teori yang berkaitan. [2]

Pada tahun 2018 penelitian yang berujdul "Sistem pendukung pengambilan keputusan penentuan pupuk produksi kelapa sawit menggunakan fuzzy madm-saw" yang diteliti oleh Alicia Destriani Sandea. Aplikasi sistem pendukung keputusan penentuan pupuk produksi kelapa sawit menentukan nilai kepentingan setiap kriteria, nilai dari pembobotan alternatif pada setiap kriteria menggunakan metode 10 skenario pada hasil uji akurasi dinyatakan memiliki nilai tingkat akurasi sebesar $70 \%$ dengan cara membandingkan kesesuaiam hasil rekomendasi. [3]

\subsection{Sistem Pendukung Keputusan}

Menurut (Keen et al, 1978 dalam Turban et al, 2005) sistem pendukung keputusan merupakan penggabungan dari sumber daya keilmuan dan kapasitas komputer untuk mendapatkan keputusan terbaik. Sistem pendukung keputusan adalah sistem yang dibuat pada komputer guna penyelesaian masalah secara terstruktur. [4]

\subsection{Technique For Others Reference by Similarity to Ideal Solution (TOPSIS)}

Technique For Others Reference by Similarity to Ideal Solution (Topsis) merupakan salah satu metode dalam pengambilan keputusan yang memiliki kriteria lebih dari satu. Yoondan Hwang adalah yang pertama kali memperkenalkan metode ini (1981). Metode Topsis memiliki prinsip bahwa untuk menentukan kedekatan dari suatu alternatif menggunakan jarak Eucladian untuk menentukannya, nilai dari alternatif yang terpilih harus mendekati jarak terjauh dari solusi ideal positif dari solusi ideal negatif. Seluruh jumlah nilai terbaik yng harus dicapai semua atribut merupakan solusi ideal positif, sedangkan solusi ideal negatif adalah semua nilai yang dimiliki setiap atribut [5]

\subsection{Weight Product (WP)}

Menurut Kusumadewi (2006), metode Wp menerapkan teknik perkalian untuk menghubungkan antar nilai rating atribut. Dimana terlebih dahulu nilai rating tiap atribut dipangkatkan terlebih dahulu dengan bobot atribut yang berkaitan. Untuk menentukan nilai preferensi alternatif adalah sebagai berikut :

$$
S_{i}=\prod_{j=1}^{n} X_{i j}{ }^{W_{j}} ; \text { dengan } \mathrm{i}=1,2, \ldots, \mathrm{m}
$$

.. Persamaan 2.1

Dimana :

$\mathrm{S}_{\mathrm{i}}=$ Nilai vektor

$\mathrm{X}_{\mathrm{ij}}=$ Nilai alternatif terhadap kriteria

$\mathrm{W}_{\mathrm{j}}=$ Pangkat bobot bernilai positif untuk atribut keuntungan, dan bernilai negatif untuk atribut biaya.

Dengan nilai $\sum=1$ adalah pangkat yang bernilai negatif untuk atribut biaya, sedangkan apabila bernilai positif maka diartikan sebagai atribut keuntungan. Langkah-langkah perhitungan metode Wp sebagai berikut :

a. Melakukan perbaikan bobot terlebih dahulu agar total bobot $\sum=1$. Caranya dengan membagi nilai bobot dengan penjumlahan seluruh bobot.

b. Mengalikan seluruh atribut untuk sebuah alternatif dengan bobot sebagai pangkat positif untuk atribut keuntungan dan bobot pangkat negatif pada atribut biaya disebut vector $S_{i}$

c. Hasil perkalian dijumlahkan untuk menghasilkan nilai pada setiap alternatif.

d. Melakukan pembagian antara $S_{i}$ dan hasil penjumlahan $\left(\sum\right)$ yang akan menghasilkan nilai preferensi $\mathrm{V}_{\mathrm{i}}$. [6] 


\section{METODE PENELITIAN}

\subsection{Analisis Kebutuhan}

Setelah melakukan pengumpulan data yang telah dikumpulkan maka dilakukan analisis data untuk memperoleh kesimpulan. Proses analisis merupakan melakukan analisa terhadap aplikasi agar sistem yang ada dapat lebih baik dan lengkap fitur-fitur yang dibutuhkan. Kebutuhan mencakup dua hal yaitu kebutuhan fungsional dan kebutuhan non fungsional.

\subsection{Kebutuhan Fungsional}

Kebutuhan fungsional merupakan kebutuhan yang berisi fitur apa saja yang ada pada aplikasi tersebut Berikut adalah kebutuhan fungsional yang ada pada aplikasi ini adalah sebagai berikut :

a. Aplikasi dapat melakukan validasi login bagi admin.

b. Aplikasi dapat melakukan proses input data kabupaten bagi admin.

c. Aplikasi dapat melakukan proses input data kecamatan bagi admin.

d. Aplikasi dapat melakukan proses input data jenis pupuk bagi admin.

e. Aplikasi dapat melakukan proses input data kerusakan tanaman bagi admin.

f. Aplikasi dapat mengolah data kriteria

g. Aplikasi dapat mengolah data alternatif

h. Aplikasi dapat melakukan penilaian berupa perangkingan data pupuk yang optimal sesuai dengan alternatif dan kriteria.

i. Aplikasi dapat menghitung besaran pupuk yang akan digunakan menggunakan luas lahan.

\subsection{Kebutuhan Non Fungsional}

Kebutuhan non fungsional yang berkaitan erat dengan aspek kualitas perangkat lunak terkait pada fitur yang ada di sistem. Kebutuhan non fungsional antar muka pengguna meliputi :

1) Perangkat keras

a. Processor Intel ${ }^{\circledR}$ Core $^{\mathrm{TM}} \mathrm{i} 5-3210 \mathrm{M} 2.5 \mathrm{GHz}$

b. Random acces memory (RAM ) 6 GB

c. Laptop Toshiba-Satellite C40-

2) Perangkat Lunak

a. Sistem dijalankan pada sistem operasi windows 10.

b. Sistem dijalankan pada beberapa perangkat lunak web browser antara lain netbox, mozilla firefox, dan google chrome.

c. Sistem server dengan web server apache serta MySQL sebagai databasenya.

d. Sistem menggunakan Bahasa pemrograman codeigniter 4 (framework PHP)

3) Kebutuhan Informasi

a. Informasi mengenai jenis pupuk dan kerusakan tanaman padi.

b. Keamanan data di daerah, karena hanya admin yang dapat mengakses data tersebut.

4) Kebutuhan Kinerja

a. Jaringan internet yang tidak dibatasi bandwith. b. Ketepatan perhitungan dalam rekomendasi pupuk tanaman padi.

5) Kebutuhan pengguna

a. Terdapat pengguna sebagai admin sebagai pengatur nilai kriteria dan alternatif.

b. Terdapat pengguna sebagai user yang dapat melihat

c. CPU server dengan kecepatan clock lebih dari 2.0 GhZ untuk performa yang lebih baik.

d. Kapasitas RAM minimal 1024 MB atau lebih.

e. Internet dengan bandwith yang tidak dibatasi.

\subsection{Struktur Menu}

Struktur menu merupakan gambaran dari alur yang menunjukkan fitur apa saja yang dimiliki oleh aplikasi.

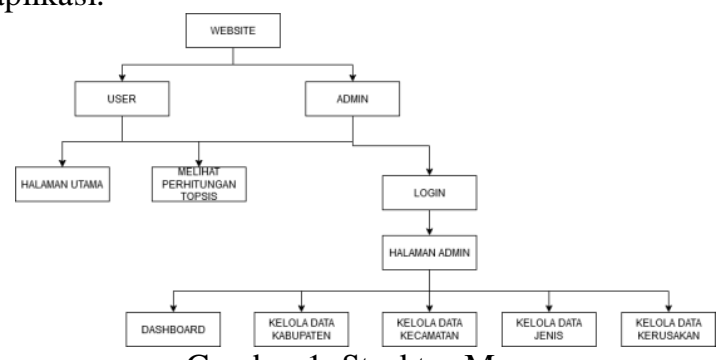

Gambar 1. Struktur Menu

Pada gambar 1 struktur menu di atas dapat dijelaskan bahwa user hanya bisa melihat halaman utama, dan halaman perhitungan topsis. Sedangkan untuk admin dapat melakukan login, melihat halaman utama, mengelola data kabupaten, mengelola data kecamatan, melihat perhitungan topsis, mengelola data jenis, dan mengelola data kerusakan.

\subsection{Data Flow Diagram}

Perancangan data flow diagram (DFD) dalam alur perancangan aplikasi website menggunakan metode Technique For Others Reference by Similarity to Ideal Solution dan Weight Product dapat dilihat pada gambar 2 dan 3 .

a. DFD Level 0

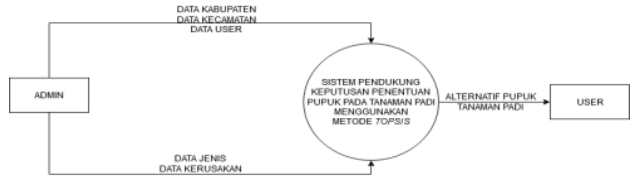

Gambar 2 Data Flow Diagram Level 0

Pada gambar 2 dapat diketahui bahwa admin dapat menambahkan data kabupaten, data kecamatan, data user, data jenis pupuk, dan data kerusakan tanaman kemudian data yang sudah disimpan akan masuk pada proses aplikasi penentuan pupuk pada tanaman padi menggunakan metode Technique For Others Reference by Similarity to Ideal Solution dan Weight Product. Dari proses akan keluar hasil berupa alternatif rekomendasi pupuk pada tanaman padi yang selanjutnya dapat dilihat oleh user untuk menentukan pupuk tanaman padi. 
b. DFD Level 1

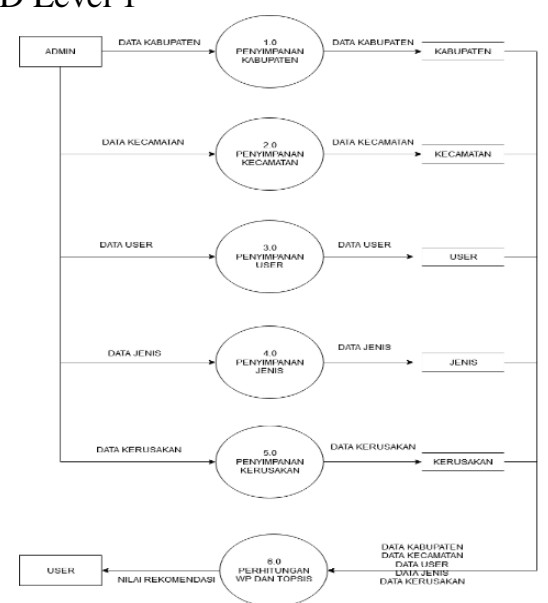

Gambar 3 DFD Level 1

Pada gambar 3 dapat dilihat proses 1.0 admin menambahkan data kabupaten masuk ke proses penyimpanan data kabupaten dan disimpan pada tabel kabupaten, pada proses 2.0 admin menambahkan data kecamatan masuk ke proses penyimpanan data kecamatan dan disimpan pada tabel kecamatan, pada proses 3.0 admin menambahkan data user masuk ke proses penyimpanan data user dan disimpan pada tabel user, pada proses 4.0 admin menambahkan data jenis masuk ke proses penyimpanan data jenis dan disimpan pada tabel jenis, , pada proses 5.0 admin menambahkan data kerusakan masuk ke proses penyimpanan data kerusakan dan disimpan pada tabel kerusakan.

\subsection{Flowchart Sistem}

Flowchart sistem menunjukkan alur kerja aplikasi atau proses dari awal berjalannya sistem hingga akhir, alur ini menggambarkan langkah umum dari awal sistem dijalankan hingga proses akhir merekomendasikan pupuk tanaman padi ditunjukkan pada gambar 3 .

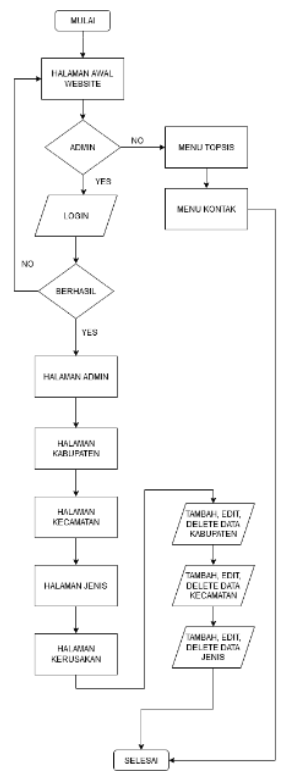

Gambar 4 Flowchart Sistem
Berdasarkan pada gambar 4 halaman login terdapat hak akses sebagai admin. Jika ada kegagalan pada saat memasukkan username dan password maka akan tetap berada di halaman login, jika login berhasil admin dapat mengolah halaman kabupaten, halaman kecamatan, halaman jenis, dan halaman kerusakan. Sedangkan untuk user tidak perlu memerlukan login untuk mengakses apliasi tersebut. Pada saat membuka aplikasi tersebut user dapat memilih menu topsis atau kontak, Ketika user memilih menu topsis harus memasukkan data berupa kabupaten, dan 6 jenis dosis pupuk. User dapat melihat proses perhitungan topsis sampai perangkingan.

\subsection{Flowchart Metode TOPSIS}

Flowchart metode Topsis ini menjelaskan proses perhitungan metode ditunjukkan pada gambar 5 .

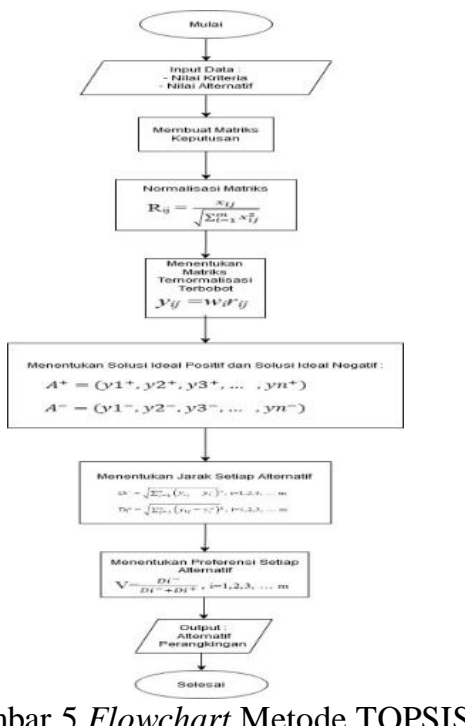

Pada Gambar 5 menunjukkan flowchart metode Topsis, Langkah yang pertama memasukkan nilai dari kriteria, kemudian Langkah yang kedua menentukan bobot dari kriteria. Langkah ketiga melakukan perhitungan matriks keputusan ternormalisasi dan melakukan perhitungan matriks keputusan ternormalisasi terbobot. Kemudian menentukan nilai solusi ideal negatif dan positif. Setelah mendapatkan nilai solusi ideal negatif dan solusi ideal positif langkah selanjutnya menentukan nilai preferensi atau perangkingan yang ditentukan dari jarak setiap alternatif.

\subsection{Flowchart Metode WP}

Flowchart metode WP ini menjelaskan proses perhitungan metode ditunjukkan pada gambar 6 


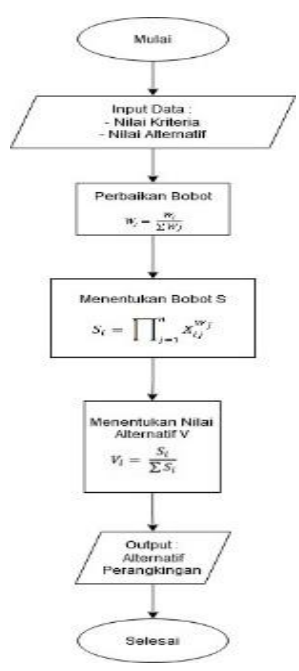

Gambar 6 Flowchart Metode TOPSIS

Pada gambar 6 menunjukkan metode Weight Product, dimulai dengan memasukkan nilai alternatif dan kriteria, melakukan perbaikan bobot untuk masing-masing kondisi tanaman dan dosis pupuk, kemudian menghitung bobot vektor masing-masing kondisi tanaman dan dosis pupuk, terakhir menentukan nilai alternatif perangkingan.

\subsection{Flowchart Metode Gabungan}

Flowchart dari metode gabungan yaitu metode Technique for Order Performance by Similarity to Ideal Solution (Topsis) dan Weight Product (Wp) seperti pada gambar 7

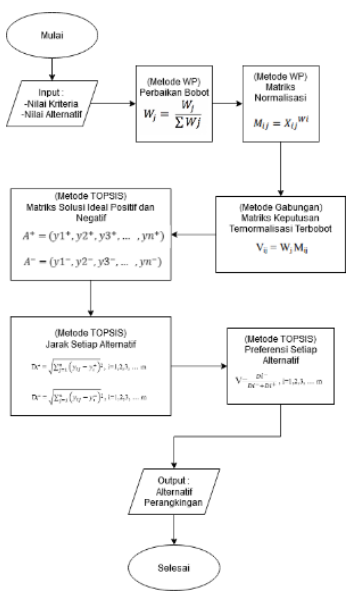

Gambar 7 Flowchart Metode Gabungan

Pada Gambar 7 menunjukkan metode gabungan dari metode Technique for Order Performance by Similarity to Ideal Solution dan Weight Product. Sebelum dilakukan perhitungan, memasukkan nilai alternatif dan nilai kriteria. Kemudian, pada aplikasi ini menggunakan 2 metode penggabungan dari kedua metode tersebut, Langkah pertama melakukan perbaikan bobot menggunakan metode Weight Product, kedua melakukan matriks normalisasi pada kriteria tersebut, langkah ketiga melakukan matriks keputusan ternormalisasi terbobot menggunakan metode Technique for Order Performance by Similarity to Ideal Solution kemudian mencari nilai maksimum dan minimum dari kriteria masing-masing, keempat mencari nilai matriks solusi ideal negatif dan positif menggunakan metode Topsis, Langkah terakhir mencari jarak setiap alternatif pada metode Topsis, dan melakukan proses perhitungan nilai preferensi menggunakan metode Topsis.

\subsection{Perhitungan Metode (TOPSIS dan WP)}

Sampel yang digunakan untuk penentuan pupuk terbaik menggunakan penggabungan kedua metode diambil data 1 kabupaten dengan 6 alternatif dan 8 kriteria sebagai berikut :

a. Pembobotan kerusakan tanaman

Tabel 1 Pembobotan kerusakan tanaman

\begin{tabular}{|c|c|c|}
\hline No & Kriteria & Bobot \\
\hline 1 & Status banjir padi & 3 \\
\hline 2 & Status Kekeringan Padi & 3 \\
\hline 3 & $\begin{array}{c}\text { Status OPT Wereng } \\
\text { Batang Coklat }\end{array}$ & 5 \\
\hline 4 & $\begin{array}{c}\text { Status OPT Tikus } \\
\text { Sawah }\end{array}$ & 4 \\
\hline 5 & $\begin{array}{c}\text { Status OPT Penggerek } \\
\text { Batang Padi }\end{array}$ & 3 \\
\hline 6 & Status OPT Tungro & 5 \\
\hline 7 & Status OPT Blast & 1 \\
\hline
\end{tabular}

\section{Keterangan Bobot Nilai Kriteria :}
5: Aman
$4:$ Rendah
3 : Sedang
2 : Tinggi
1 : Sangat Tinggi

b. Pembobotan data dosis pupuk

Tabel 2 Pembobotan dosis pupuk

\begin{tabular}{|c|c|c|}
\hline No & Kriteria & Bobot \\
\hline 1 & $\begin{array}{c}\text { Non Organik NPK } \\
15-15-15\end{array}$ & 5 \\
\hline 2 & Non Organik Urea & 2 \\
\hline 3 & Non Organik ZA & 2 \\
\hline 4 & $\begin{array}{c}\text { Organik NPK 15- } \\
15-15\end{array}$ & 4 \\
\hline 5 & Organik Urea & 2 \\
\hline 6 & Organik ZA & 2 \\
\hline
\end{tabular}

Keterangan Bobot Nilai Kriteria :

$1: 50-99(\mathrm{Kg} / \mathrm{ha})$

$2: 100-149(\mathrm{Kg} / \mathrm{ha})$

$3: 150-199(\mathrm{Kg} / \mathrm{ha})$

$4: 200-299(\mathrm{Kg} / \mathrm{ha})$

$5: 300-350(\mathrm{Kg} / \mathrm{ha})$

1. Langkah pertama melakukan perbaikan bobot meggunakan metode WP.

Tabel 3 Bobot Awal

\begin{tabular}{|l|l|l|l|l|l|l|l|}
\hline \multicolumn{7}{|c|}{$\mathrm{w}$} \\
\hline 3 & 4 & 3 & 3 & 1 & 2 & 4 & 5 \\
\hline
\end{tabular}


$\mathrm{W} 1=3 /(3+4+3+3+1+2+4+5)=0,12$

$\mathrm{W} 2=4 /(3+4+3+3+1+2+4+5)=0,16$

$\mathrm{W} 3=3 /(3+4+3+3+1+2+4+5)=0,12$

$\mathrm{W} 4=3 /(3+4+3+3+1+2+4+5)=0,12$

$\mathrm{W} 5=1 /(3+4+3+3+1+2+4+5)=0,04$

$\mathrm{W} 6=2 /(3+4+3+3+1+2+4+5)=0,08$

$\mathrm{W} 7=4 /(3+4+3+3+1+2+4+5)=0,16$

$\mathrm{W} 8=5 /(3+4+3+3+1+2+4+5)=0,12$

2. Langkah kedua menghitung matriks keputusan normalisasi menggunakan metode wp

$\mathrm{M} 11=3^{0,12}=1,140918$

$\mathrm{M} 12=3^{0,16}=1,192173$

$\mathrm{M} 13=5^{0,12}=1,213043571$

$\mathrm{M} 14=4^{0,12}=1,180993$

Tabel 4 Matriks keputusan normalisasi

\begin{tabular}{|c|c|c|c|c|c|c|c|c|}
\hline Kriteria & C1 & C2 & C3 & C4 & C5 & C6 & C7 & C8 \\
\hline A1 & 1,14 & 1,19 & 1,21 & 1,18 & 1,04 & 1,13 & 1 & 1,37 \\
\hline A2 & 1,14 & 1,19 & 1,21 & 1,18 & 1,04 & 1,13 & 1 & 1,14 \\
\hline A3 & 1,14 & 1,19 & 1,21 & 1,18 & 1,04 & 1,13 & 1 & 1,14 \\
\hline A4 & 1,14 & 1,19 & 1,21 & 1,18 & 1,04 & 1,13 & 1 & 1,31 \\
\hline A5 & 1,14 & 1,19 & 1,21 & 1,18 & 1,04 & 1,13 & 1 & 1,14 \\
\hline A6 & 1,14 & 1,19 & 1,21 & 1,18 & 1,04 & 1,13 & 1 & 1,14 \\
\hline
\end{tabular}

3. Langkah ketiga, menghitung matriks keputusan ternormalisasi terbobot metode gabungan

$\mathrm{V} 11=3 * 1,140918=3,422755$

$\mathrm{V} 12=4 * 1,192173=4,78693$

$\mathrm{V} 13=3 * 1,213043571=3,639130714$

$\mathrm{V} 14=3 * 1,180993=3,542978$

Tabel 5 Matriks Keputusan Ternormalisasi Terbobot

\begin{tabular}{|l|l|l|l|l|l|l|l|l|}
\hline & C1 & C2 & C3 & C4 & C5 & C6 & C7 & C8 \\
\hline A1 & 3,4 & 4,7 & 3,6 & 3,5 & 1,04 & 2,2 & 4 & 6,8 \\
\hline A2 & 3,4 & 4,7 & 3,6 & 3,5 & 1,04 & 2,2 & 4 & 5,7 \\
\hline A3 & 3,4 & 4,7 & 3,6 & 3,5 & 1,04 & 2,2 & 4 & 5,7 \\
\hline A4 & 3,4 & 4,7 & 3,6 & 3,5 & 1,04 & 2,2 & 4 & 6,5 \\
\hline A5 & 3,4 & 4,7 & 3,6 & 3,5 & 1,04 & 2,2 & 4 & 5,7 \\
\hline A6 & 3,4 & 4,7 & 3,6 & 3,5 & 1,04 & 2,2 & 4 & 5,7 \\
\hline max & 3,4 & 4,7 & 3,6 & 3,5 & 1,04 & 2,2 & 4 & 6,8 \\
\hline min & 3,4 & 4,7 & 3,6 & 3,5 & 1,04 & 2,2 & 4 & 5,7 \\
\hline
\end{tabular}

4. Langkah keempat menentukan solusi ideal positif dan negatif

$$
\begin{aligned}
& \mathrm{A} 1^{+}=(3,422755-3,422755)^{2}=0 \\
& \mathrm{~A} 2^{+}=(3,422755-3,422755)^{2}=0 \\
& \mathrm{~A} 1^{-}=(3,422755-3,422755)^{2}=0 \\
& \mathrm{~A} 2^{-}=(3,422755-3,422755)^{2}=0
\end{aligned}
$$

Tabel 6 Solusi Ideal Positif

\begin{tabular}{|c|c|c|c|c|c|c|c|c|}
\hline & C1 & C2 & C3 & C4 & C5 & C6 & C7 & C8 \\
\hline A1 & 0 & 0 & 0 & 0 & 0 & 0 & 0 & 0 \\
\hline A2 & 0 & 0 & 0 & 0 & 0 & 0 & 0 & 1,33 \\
\hline A3 & 0 & 0 & 0 & 0 & 0 & 0 & 0 & 1,33 \\
\hline A4 & 0 & 0 & 0 & 0 & 0 & 0 & 0 & 0,09 \\
\hline A5 & 0 & 0 & 0 & 0 & 0 & 0 & 0 & 1,33 \\
\hline A6 & 0 & 0 & 0 & 0 & 0 & 0 & 0 & 1,33 \\
\hline
\end{tabular}

Tabel 7 Solusi Ideal Negatif

\begin{tabular}{|c|c|c|c|c|c|c|c|c|}
\hline & C1 & C2 & C3 & C4 & C5 & C6 & C7 & C8 \\
\hline A1 & 0 & 0 & 0 & 0 & 0 & 0 & 0 & 1,33 \\
\hline A2 & 0 & 0 & 0 & 0 & 0 & 0 & 0 & 0 \\
\hline A3 & 0 & 0 & 0 & 0 & 0 & 0 & 0 & 0 \\
\hline A4 & 0 & 0 & 0 & 0 & 0 & 0 & 0 & 0,72 \\
\hline A5 & 0 & 0 & 0 & 0 & 0 & 0 & 0 & 0 \\
\hline A6 & 0 & 0 & 0 & 0 & 0 & 0 & 0 & 0 \\
\hline
\end{tabular}

5. Langkah kelima menghitung jarak setiap alternatif dengan matriks solusi ideal

$$
\begin{aligned}
& \mathrm{A}^{+}=\sqrt{ } 0+0+0+0+0+0+0+0=0 \\
& \mathrm{~A}^{-}=\sqrt{ } \mathrm{O}+0+0+0+0+0+0+1,334387=1,155157
\end{aligned}
$$

Tabel 8 Jarak Setiap Alternatif

\begin{tabular}{|c|c|c|}
\hline & A+ & A- \\
\hline A1 & 0 & 1,155157 \\
\hline A2 & 1,155157 & 0 \\
\hline A3 & 1,155157 & 0 \\
\hline A4 & 0,301109 & 0,854048 \\
\hline A5 & 1,155157 & 0 \\
\hline A6 & 1,155157 & 0 \\
\hline
\end{tabular}

6. Langkah keenam menentukan nilai preferensi untuk setiap alternatif $(\mathrm{V})$

$\mathrm{V} 1(\mathrm{~A} 1)=0 /(0+1,155157)=1$

Tabel 9 Nilai Preferensi

\begin{tabular}{|c|c|}
\hline $\mathrm{A} 1$ & 1 \\
\hline $\mathrm{A} 2$ & 0 \\
\hline $\mathrm{A} 3$ & 0 \\
\hline $\mathrm{A} 4$ & 0,739335 \\
\hline $\mathrm{A} 5$ & 0 \\
\hline $\mathrm{A} 6$ & 0 \\
\hline
\end{tabular}

\section{HASIL DAN PEMBAHASAN}

Dalam penelitian ini, skematis pengujian meliputi tampilan aplikasi dan pengujian fungsionalitas dijelaskan sebagai berikut :

\subsection{Tampilan Awal Aplikasi}

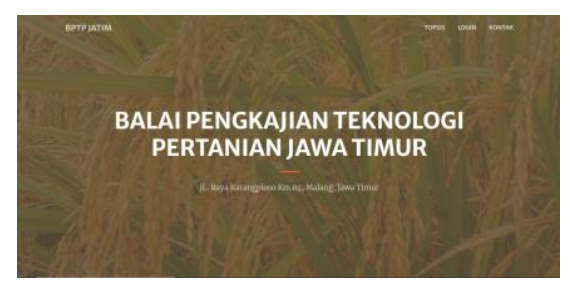

Gambar 6 Tampilan Awal Aplikasi

Berdasarkan pada tampilan gambar 6 merupakan halaman awal dari aplikasi, terdapat menu login untuk mengakses halaman admin, menu topsis dan menu kontak. 


\subsection{Tampilan Menu TOPSIS dan WP}

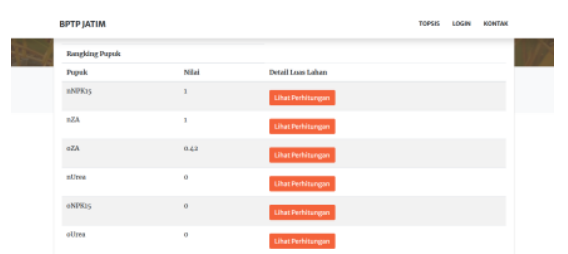

Gambar 7 Tampilan Menu TOPSIS

Berdasarkan pada tampilan gambar 7 tampilan menu merupakan tampilan perhitungan metode topsis.

\subsection{Tampilan Luas Lahan}

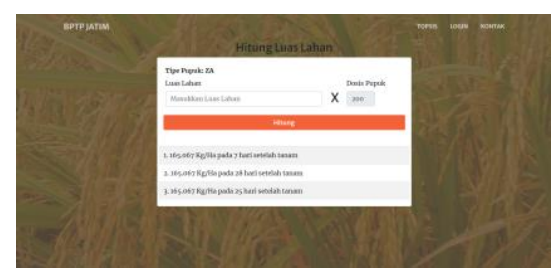

Gambar 8 Tampilan Perhitungan Dosis

Berdasarkan pada tampilan gambar 8 merupakan tampilan dimana perhitungan dosis yang digunakan sesuai kebutuhan lahan.

\subsection{Tampilan Menu Kontak}

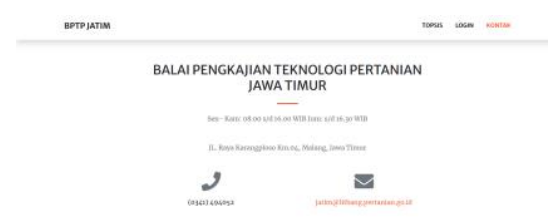

Gambar 9 Tampilan Menu Kontak

Berdasrkan pada tampilan gambar 9 merupakan tampilan kontak Balai Pengkajian Teknologi Pangan (BPTP)

\subsection{Tampilan Login}

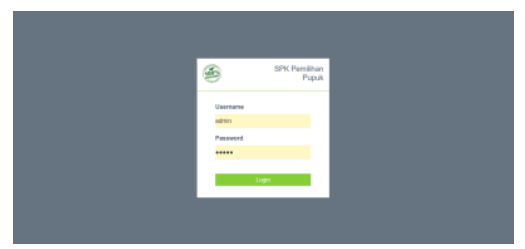

Gambar 10 Tampilan Login

Berdasarkan pada tampilan gambar 10 merupakan tampilan gambar login, dimana admin memasukkan username dan password terlebih dahulu sebelum mengakses aplikasi pemilihan pupuk pada tanaman padi.

\subsection{Tampilan Data Kabupaten}

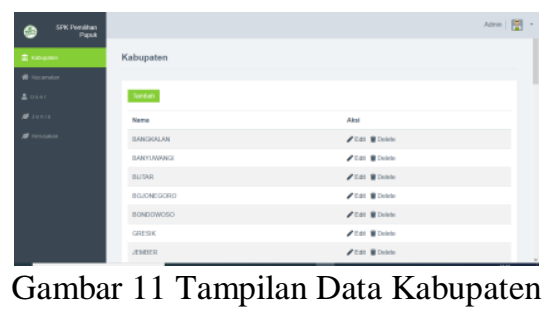

Berdasarkan pada tampilan gambar 11 dimana admin dapat menginputkan data-data kabupaten di Jawa Timur.

\subsection{Tampilan Data Kecamatan}

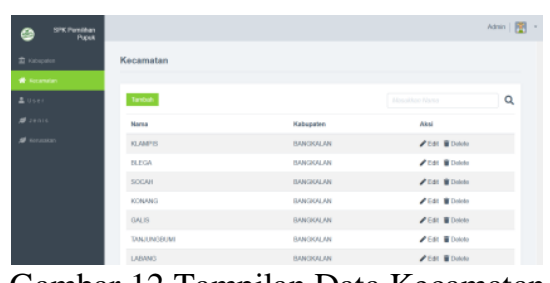

Gambar 12 Tampilan Data Kecamatan

Berdasarkan pada tampilan gambar 12 merupakan tampilan admin dimana terdapat fitur untuk admin menginputkan data kecamatan di Jawa Timur.

\subsection{Tampilan Data Jenis}

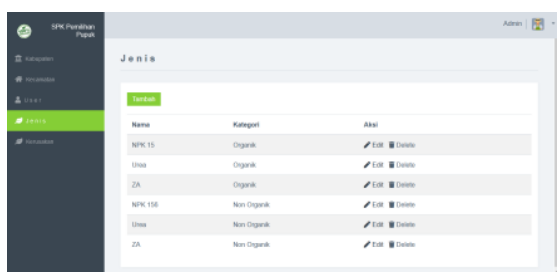

Gambar 13 Tampilan Data Jenis

Berdasarkan pada tampilan gambar 13 merupakan tampilan dimana admin menginputkan data-data jenis atau kriteria di Jawa Timur

\subsection{Tampilan Perhitungan Metode}

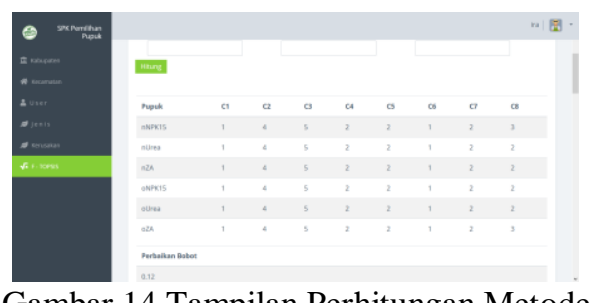

Gambar 14 Tampilan Perhitungan Metode

Berdasarkan pada tampilan gambar 14 merupakan tampilan proses perhitungan penggabungan metode TOPSIS dan WP yang dapat dilihat oleh admin. 


\subsection{Tampilan Data Kerusakan}

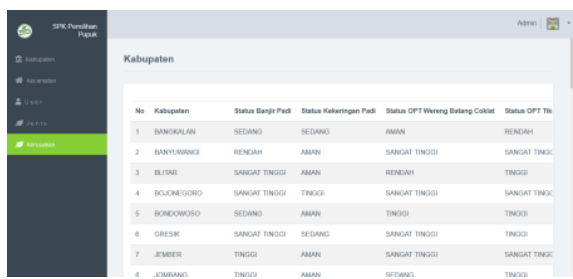

Gambar 15 Tampilan Data Kerusakan

Berdasarkan pada gambar 15 merupakan tampilan dimana admin melihat data-data kerusakan atau kriteria di Jawa Timur

\subsection{Pengujian Fungsionalitas Sistem}

Pengujian pada fungsionalitas sistem dilakukan dengan melakukan pengujian sistem yang dinyatakan sukses Ketika kebutuhan sistem pada tabel 4.1 dapat berjalan sesuai dengan rancangan kebutuhan. Pengujian yang dilakukan dengan web server xampp versi 3.2.2 (MF) dan browser mozila firefox 63.0.2 (32bit), (ME) Microsoft Edge, dan Netbox.

Tabel 11 Pengujian Fungsionalitas Sistem

\begin{tabular}{|c|c|c|c|c|}
\hline \multirow{2}{*}{$\begin{array}{l}\mathrm{N} \\
\mathrm{O}\end{array}$} & \multirow{2}{*}{$\begin{array}{c}\text { Fungsionalita } \\
\text { s }\end{array}$} & \multicolumn{3}{|c|}{ Nama Browser } \\
\hline & & $\begin{array}{l}\text { Mozill } \\
\text { a } \\
\text { Firefox }\end{array}$ & $\begin{array}{l}\text { Chrom } \\
\text { e }\end{array}$ & $\begin{array}{l}\text { Netbo } \\
\mathrm{x}\end{array}$ \\
\hline 1 & Halaman awal & $\sqrt{ }$ & $\sqrt{ }$ & $\sqrt{ }$ \\
\hline 2 & Menu topsis & $\sqrt{ }$ & $\sqrt{ }$ & $\sqrt{ }$ \\
\hline 3 & Menu kontak & $\sqrt{ }$ & $\sqrt{ }$ & $\sqrt{ }$ \\
\hline 4 & $\begin{array}{l}\text { Halaman } \\
\text { login }\end{array}$ & $\sqrt{ }$ & $\sqrt{ }$ & $\sqrt{ }$ \\
\hline 5 & $\begin{array}{l}\text { Halaman data } \\
\text { kabupaten }\end{array}$ & $\sqrt{ }$ & $\sqrt{ }$ & $\sqrt{ }$ \\
\hline 6 & $\begin{array}{l}\text { Halaman data } \\
\text { kecamatan }\end{array}$ & $\sqrt{ }$ & $\sqrt{ }$ & $\sqrt{ }$ \\
\hline 7 & $\begin{array}{l}\text { Halaman data } \\
\text { jenis }\end{array}$ & $\sqrt{ }$ & $\sqrt{ }$ & $\sqrt{ }$ \\
\hline 8 & $\begin{array}{l}\text { Halaman data } \\
\text { kerusakan }\end{array}$ & $\sqrt{ }$ & $\sqrt{ }$ & $\sqrt{ }$ \\
\hline
\end{tabular}

Dimana :

$\sqrt{ }=$ Berhasil

$\mathrm{X}=$ Gagal

Pada tabel 10 pengujian fungsionalitas sistem fungsi-fungsi aplikasi seperti halaman utama user, halaman kontak, halaman perhitungan metode wp dan topsis , halaman kabupaten, halaman kecamatan, halaman jenis, halaman kerusakan dan halaman login dapat berfungsi dengan baik pada ketiga browser tersebut.

\section{KESIMPULAN DAN SARAN}

\subsection{Kesimpulan}

Berdasarkan hasil Analisa dan pengujian terhadap penggabungan metode dalam menentukan pupuk tanaman padi dapat disimpulkan bahawa :
1. Penelitian ini melibatkan penentuan pupuk tanaman padi sehingga mendapatkan tingkat keakurasian pada setiap metode dan menggunakan data alternatif sebanyak 6 jenis pupuk tanaman padi.

2. Berdasarkan pengujian fungsionalitas sistem dapat berjalan dengan seluruh fitur sesuai rancangan kebutuhan yang telah diuji menggunakan tiga browser yaitu netbox, Mozilla Firefox, dan Google Chrome.

3. Penentuan penggunaan dosis pupuk yang diperlukan dilakukan dengan cara hasil pengkalian dari dosis pupuk yang terpilih dan luas lahan.

4. Gabungan dari metode Technique for Order Performance by Similarity to Ideal Solution dan Weight Product cukup efektif karena selisih hasil perhitungan sistem dan manual memiliki nilai 0,089946. Hal ini dapat dinyatakan pada perhitungan manual dan sistem mengalami kesesuaian.

5. Berdasarkan pengujian yang telah dilakukan pada tabel 9 nilai preferensi menunjukkan nilai rekomendasi pupuk non organik npk 15-15-15 dengan nilai preferensi 1 sebagai pupuk terbaik dengan kondisi kerusakan tanaman dan dosis yang akan digunakan.

\subsection{Saran}

Berikut merupakan saran untuk pengembangan dari penelitian aplikasi ini dan menjadi lebih baik untuk kedepannya adalah sebagai berikut :

1. Data yang digunakan merupakan data kuantitatif, maka dari itu disarankan untuk penelitian selanjutnya dapat menggunakan kombinasi metode seperti Simple Additive Weighting (Saw) dan Analytical Hierarchy Process (AHP). Kedua metode tersebut saling berhubungan karena di hasil akhir perhitungan penentuan pupuk menggunakan metode AHP akan diakumulasikan dengan jumlah perhitungan penentuan pupuk yang sebelumnya telah dihitung menggunakan metode SAW.

2. Upaya agar meningkatkan hasil akurasi yang dibutuhkan antara lain penambahan kriteria seperti curah hujan dan penggunaan lahan agar pada basis pengetahuan mendapatkan nilai yang spesifik untuk dosis pupuk.

\section{DAFTAR PUSTAKA}

[1] Wahyuni Yahyan, M. I. (2020). PEMILIHAN PUPUK PADA TAMANAM PADI BERBASIS WEB UNTUK MENINGKATKAN HASIL PANEN DENGAN MENGGUNAKAN METODHE ANALITICAL HIERARCY PROSES.

http://jurnal.umsb.ac.id/index.php/RANGTEKNI KJOURNAL.

[2] Erwin Hermawan, R. H. (2017). Sistem Pendukung Keputusan Pemilihan Pupuk Untuk Tanaman Padi Menggunakan Metode Fuzzy.

[3] Sandea, Alicia Destriani. (2018). SISTEM 
PENDUKUNG

KEPUTUSAN

PENGAMBILAN

PRODUKSI

PENENTUAN PUPUK

KELAPA SAWIT

MENGGUNAKAN FUZZY MADM-SAW.

repository.usd.ac.id.

[4] Labolo, A. Y. (2019). SISTEM PENDUKUNG KEPUTUSAN PEMBERIAN BANTUAN PUPUK KEPADA KELOMPOK TANI MENGGUNAKAN METODE PROFILE MATCHING.
[5] Ade Ragil Purwandani, A. Y. (2019). ANALISIS EFEKTIFITAS METODE WEIGHTED PRODUCT DAN TOPSIS DALAM MENDIAGNOSA SERANGAN ASMA.

[6] Zaenal Alamsyah, D. G. (2019). SISTEM PENDUKUNG KEPUTUSAN MENGGUNAKAN METODE WEIGHTED PRODUCT DAN SIMPLE ADDITIVE WEIGHTING TERHADAP PENERIMAAN GURU. 